\title{
Growth of intermetallic compounds in the Au-In system: Experimental study and 1-D modelling
}

\author{
L. Deillon ${ }^{\mathrm{a}, \mathrm{b}, \mathrm{c}, *, 1}$, T. Hessler ${ }^{\mathrm{a}}$, A. Hessler-Wyser ${ }^{\mathrm{c}}$, M. Rappaz $^{\mathrm{b}}$ \\ ${ }^{a}$ The Swatch Group R\&D S.A., division Asulab, 2074 Marin, Switzerland \\ ${ }^{\mathrm{b}}$ Laboratoire de Simulation des Matériaux, École Polytechnique Fédérale de Lausanne, 1015 Lausanne, Switzerland \\ ${ }^{\mathrm{c}}$ Centre Interdisciplinaire de Microscopie Électronique, École Polytechnique Fédérale de Lausanne, 1015 Lausanne, Switzerland
}

Received 7 January 2014; received in revised form 10 June 2014; accepted 11 July 2014

Available online 16 August 2014

\begin{abstract}
The gold-indium system is of primary interest for bonding processes such as solid-liquid interdiffusion bonding. In order to optimize the manufacturing parameters, it is essential to know which intermetallic compounds (IMCs) are formed when solid Au and liquid In are brought into close contact with each other, and what are their growth kinetics. For this purpose, we fabricated diffusion couples above and below the melting point of $\mathrm{In}$ (for $T=250$ and $150{ }^{\circ} \mathrm{C}$ respectively). Three IMCs, identified as AuIn $2, \mathrm{AuIn}_{\mathrm{In}} \mathrm{and} \mathrm{Au}_{7} \mathrm{In}_{3}$, are always observed in the reaction zone, even after short times. AuIn $\mathrm{Is}_{2}$ the thickest and fastest growing layer and AuIn is only present as a thin layer. Whereas AuIn $\mathrm{In}_{2}$ and AuIn exhibit an equiaxed structure, $\mathrm{Au}_{7} \mathrm{In}_{3}$ is found to grow as columnar grains. The diffusion coefficients in each phase were determined by means of a 1-D finite difference modelling of In diffusion. The values are consistent and can be used to predict the growth rate as a function of temperature and time, i.e. to simulate a whole bonding process with finite thicknesses.
\end{abstract}

(C) 2014 Acta Materialia Inc. Published by Elsevier Ltd. All rights reserved.

Keywords: Gold; Indium; Diffusion; Intermetallic compounds growth

\section{Introduction}

Microelectromechanical systems (MEMS) devices must be fabricated in a way that allows them to subsequently become parts of more complex structures without being damaged during the assembly steps. Several bonding steps occur throughout the whole process and, during each of them, the integrity of the previous bond must be preserved. Solid-liquid interdiffusion (SLID) bonding is thus an advantageous way of achieving hermetic packaging for MEMS devices [1,2]. The process consists in bringing

\footnotetext{
* Corresponding author at: The Swatch Group R\&D S.A., division Asulab, 2074 Marin, Switzerland.

E-mail addresses: lea.deillon@gmail.com (L. Deillon), thierry. hessler@a3.epfl.ch (T. Hessler), aicha.hessler@epfl.ch (A. Hessler-Wyser), michel.rappaz@epfl.ch (M. Rappaz).

${ }^{1}$ Present address: Institut Jean Lamour, 54000 Nancy, France.
}

together two metallic layers with respectively high and low melting points. By heating the system to a temperature above the lowest melting point, one or more solid intermetallic compounds (IMCs) form by interdiffusion, their melting temperature usually being between those of the two initial materials. Bonds can thus be made at a low temperature, while allowing the MEMS to withstand higher temperatures in subsequent operations, such as its mounting on printed circuit boards. The process time and temperature depend strongly on the growth kinetics of the IMCs that are formed.

The gold-indium system was chosen in the present study because In melts at a low temperature $\left(156.6^{\circ} \mathrm{C}\right)$ and all the phases susceptible to forming by interdiffusion have melting points above $450{ }^{\circ} \mathrm{C}$ (see the phase diagram in Fig. 1). This system has been investigated by a few authors for temperatures below the melting point of In. Powell and 


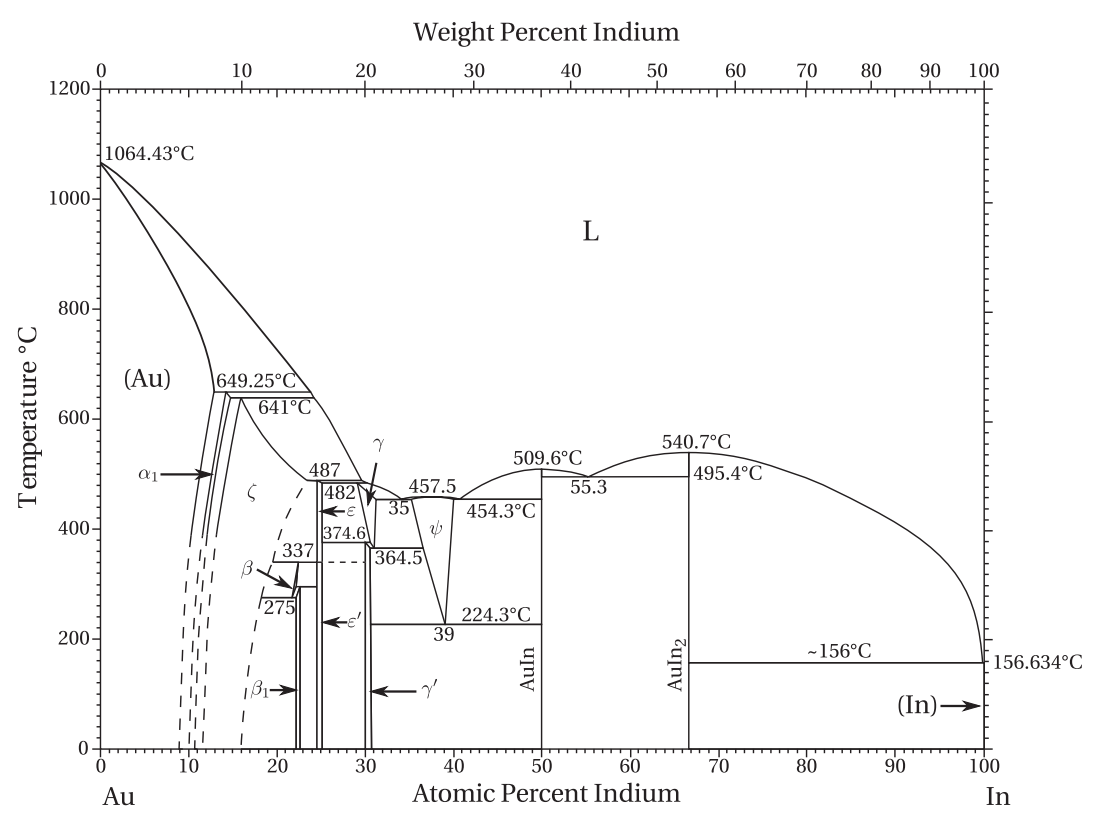

Fig. 1. The Au-In binary phase diagram [3].

Braun [4] investigated the $\mathrm{Au}-\mathrm{In}$ interdiffusion at 142 and $151{ }^{\circ} \mathrm{C}$. The major component of the reaction zone was found to be $\mathrm{AuIn}$, its growth being linear with the square root of the diffusion time. Powell and Braun noticed that In is the fastest diffusing species through this compound. The IMCs $\mathrm{Au}_{9} \mathrm{In}_{4}$ (corresponding to $\gamma^{\prime}$ in the later version of the phase diagram shown in Fig. 1), AuIn and an Au-richer phase were also observed but as much thinner layers, and thus their growth kinetics were not studied. The Au-richer phase was very thin and was assumed to be $\beta$, since at that time this was the only known IMC with a composition lying between $(\mathrm{Au})$ and $\gamma^{\prime}$. A Matano analysis allowed Powell and Braun to estimate the interdiffusion coefficients in these four IMCs and the solid solutions (see Table 1).

Jellison [5] studied the growth of $\mathrm{AuIn}_{2}$ between 40 and $125^{\circ} \mathrm{C}$ at the interface between gold wires bounded to a nearly flat indium surface. The test was not really onedimensional (1-D), and the presence of a free surface allowed the IMC to move out of this surface. The author noticed that the newly formed IMC appears at the surface of $\mathrm{Au}$, while the earlier formed grains are carried towards In, but also upwards, inducing plastic deformation in this very soft phase. She assumed a linear relationship between the reaction time and the layer thickness, but her results, at

Table 1

Interdiffusion coefficients and diffusion coefficients of In in the Au-In system at $151^{\circ} \mathrm{C}\left(\mathrm{m}^{2} \mathrm{~s}^{-1}\right)[4]$.

\begin{tabular}{lll}
\hline & $\widetilde{D}$ & $D$ \\
\hline $\mathrm{In}, 3 \%$ at. Au & $9.9 \times 10^{-17}$ & $5 \times 10^{-15}$ \\
$\mathrm{AuIn}_{2}$ & $1.8 \times 10^{-15}$ & $7.4 \times 10^{-15}$ \\
$\mathrm{AuIn}$ & $3.6 \times 10^{-16}$ & $9.1 \times 10^{-16}$ \\
$\mathrm{Au}_{7} \mathrm{In}_{3}\left(\gamma^{\prime}\right)$ & $5.8 \times 10^{-16}$ & $9.8 \times 10^{-16}$ \\
$\beta$ & $7.8 \times 10^{-17}$ & $1.1 \times 10^{-16}$ \\
$\mathrm{Au}, 9 \%$ at. In & $6.2 \times 10^{-17}$ & $7.1 \times 10^{-17}$ \\
\hline
\end{tabular}

least those at $125^{\circ} \mathrm{C}$ (only three data points), actually seem to fit a parabolic law better.

Millares et al. [6] observed the growth of $\mathrm{AuIn}_{2}$, AuIn, $\mathrm{Au}_{7} \mathrm{In}_{3}$ and a fourth phase, assumed to be $\mathrm{Au}_{4} \mathrm{In}$, in diffusion couples between 50 and $150{ }^{\circ} \mathrm{C}$. $\mathrm{AuIn}_{2}$ was found to also be the major IMC with an equiaxed grain morphology, while $\mathrm{Au}_{7} \mathrm{In}_{3}$ had a columnar structure. These authors studied the growth kinetics of $\mathrm{AuIn}_{2}$ only and found a linear relationship between thickness and time in the first stage (i.e. controlled by an interfacial reaction), which then tends to become parabolic as the thickness increases.

Liu and Chuang [7] analyzed the morphology and the growth kinetics of $\mathrm{AuIn}_{2}$ between 225 and $350{ }^{\circ} \mathrm{C}$. They observed this IMC as a continuous wavy crystalline layer and as floating islands in the In phase, and reported that the growth of the layer followed a parabolic law. To our knowledge, this is the only study of the growth of IMC in the $\mathrm{Au}-\mathrm{In}$ system above the melting point of indium.

Whereas data about the growth kinetics of $\mathrm{AuIn}_{2}$ in the temperature range suitable for a SLID process are available, there are none for the growth of other IMCs. Furthermore, there are even some discrepancies about the number of IMCs that form under certain conditions. The aim of the present work is thus to study the growth of each IMC formed below and above the melting point of indium. From these data, the diffusion coefficients within the various phases will be determined with the help of a specifically developed 1-D finite difference numerical model of diffusion coupled with thermodynamic data.

\section{Experimental}

$\mathrm{Au} / \mathrm{In}$ diffusion couples below and above the melting point of In (for $T=150$ and $250{ }^{\circ} \mathrm{C}$ respectively) were fabricated in order to measure the IMCs thicknesses as a 
function of time and temperature. The experiments at $250{ }^{\circ} \mathrm{C}$ were made by dipping a gold wire into liquid In melted from shot with a purity of 99.9999 wt.\%, under 800 mbar of Ar. The In bath was first saturated with $\mathrm{Au}$ and homogenized to minimize the dissolution of the wire. After times ranging from 225 to $625 \mathrm{~s}$, the wires were removed from the crucible and rapidly cooled down with a helium flux. The maximum dipping time at this temperature was limited due to experimental difficulties associated with large density differences, as discussed later.

The same setup was used for the experiments at $150{ }^{\circ} \mathrm{C}$ but after immersion of the wire, the indium bath was rapidly cooled down and solidified around the wire. In this case, the indium bath was not pre-saturated with gold since the solubility of $\mathrm{Au}$ in liquid $\mathrm{In}$ is almost nil just above the melting point. A transverse slice of the ingot and wire was then sealed in a quartz capsule under 300 mbar Ar and heat-treated in the solid state for various times ranging from 1 to $484 \mathrm{~h}$. The reaction times are much longer in this case because diffusion is slower than at $250{ }^{\circ} \mathrm{C}$.

$\mathrm{Au}$ wires of $99.9985 \mathrm{wt} \%$ purity with a diameter of $1 \mathrm{~mm}$ were used for experiments longer than $81 \mathrm{~h}$ at $150{ }^{\circ} \mathrm{C}$ while wires of 99.998 wt. $\%$ purity and $100 \mu \mathrm{m}$ in diameter were used for all the other cases. The obtained samples were finally cold mounted in epoxy and transverse sections were surfaced with an ultramicrotome before being analyzed using scanning electron microscopy (SEM) and backscattered electron (BSE) imaging. Energy dispersive $\mathrm{X}$-ray (EDX) analyses were performed to determine the nature of the IMCs.

Additionally, secondary ion mass spectrometry (SIMS) depth profile analyses were carried out in order to measure the In concentration profiles in Au. A dynamic SIMS (DSIMS) analysis was performed by CAMECA with an IMS 7f instrument using $\mathrm{Cs}^{+}$primary ions at $5 \mathrm{keV}$ impact energy. A time-of-flight (ToF)-SIMS analysis was also performed by Tascon $\mathrm{GmbH}$ using $\mathrm{Cs}^{+}$ions at $1 \mathrm{keV}$ for sputtering and $\mathrm{Bi}_{\mathrm{x}}^{+}$ions at $25 \mathrm{keV}$ for analysis.

\section{Results}

\subsection{Morphology of the reaction zone}

\subsubsection{Experiments at $150^{\circ} \mathrm{C}$}

At $150{ }^{\circ} \mathrm{C}$ three IMCs are always observed in the interdiffusion zone and were identified by EDX measurements as $A u I_{2}, A u I n$ and $\mathrm{Au}_{7} \operatorname{In}_{3}\left(\gamma^{\prime}\right)$. Scanning electron micrographs after various times of reaction at this temperature are shown in Fig. 2 with a brightness level directly proportional to the $\mathrm{Au}$ concentration (BSE contrast). Starting from indium on the right, a first layer of $\mathrm{AuIn}_{2}$ is observed; it is obviously the most important IMC formed during the reaction. It has a very irregular shape, forming a loose microstructure of blocky grains, with some In channels in between. The mid-layer consists of AuIn, which grows very slowly and is observed to be thin (maximum thickness of $3.6 \mu \mathrm{m}$ after $484 \mathrm{~h}$ ). The third IMC, $\mathrm{Au}_{7} \mathrm{In}_{3}$, grows more regularly and its interface with $\mathrm{Au}$ remains almost planar, even after prolonged reaction times. Some porosity is always present locally in this compound, although this is not obvious on the SEM micrographs presented in Fig. 2, especially for the longest times, because of the lower magnifications. The voids are moreover aligned in a plane located near the $\mathrm{Au}$ interface. It is also noticeable that, for short reaction times, the $\mathrm{Au}_{7} \mathrm{In}_{3} / \mathrm{AuIn}$ and $\mathrm{AuIn} / \mathrm{AuIn}_{2}$ interfaces follow the irregularities of the $\mathrm{AuIn}_{2} / \mathrm{In}_{\text {interface }}$ to some extent.

The $\mathrm{AuIn} \mathrm{In}_{2}$ microstructure at long reaction times (Fig. 2 right, $484 \mathrm{~h}$ ) looks more compact than at shorter times (Fig. 2 left and middle, 1 and $64 \mathrm{~h}$, respectively). However, it should be kept in mind that, for the longest reaction times (greater than $81 \mathrm{~h}$ ), the diameter of the Au wire was $1 \mathrm{~mm}$ instead of $100 \mu \mathrm{m}$. However, with the grain size and surface finish of the two types of wires being identical, the difference in the $\mathrm{AuIn}_{2}$ morphologies probably does not arise from that. Note also that the $\mathrm{AuIn}_{2}$ grain size increases with time and is up to several tens of micrometers after $484 \mathrm{~h}$.

Fig. 3 shows SEM micrographs of a sample treated for $324 \mathrm{~h}$ at $150{ }^{\circ} \mathrm{C}$, taken with a low-angle backscattered electrons (LABE) detector. This imaging mode yields a crystallographic contrast, provided the sample has a good quality surface. Due to the inherent softness of both $\mathrm{Au}$ and In, this could only be achieved by cross-section polishing. The grain structure of the different phases is clearly visible on these micrographs. Gold has a very fine grain structure $\left(d_{e q}=0.8 \pm 0.3 \mu \mathrm{m}\right)$, as expected for drawn wires. The growth of $\mathrm{Au}_{7} \mathrm{In}_{3}$ is columnar, with an average grain width of a few microns $(3.9 \pm 1.1 \mu \mathrm{m})$. The AuIn grain size is small $\left(d_{e q}=2.1 \pm 0.75 \mu \mathrm{m}\right)$ and is at most equal to the layer thickness. Actually, it seems to be a monolayer of grains, except in the upper parts of pictures (a) and (b), where the layer is much thicker. Concerning $\operatorname{AuIn}_{2}$, smaller grains are observed near the interfaces, with larger grains in the middle of the layer. The average grain size throughout the layer is $14.6 \pm 3.4 \mu \mathrm{m}$.

As will be shown later (see Fig. 8), the initial goldindium interface is positioned in the $\mathrm{AuIn}_{2}$ compound, at a mean distance of 1 and $10 \mu \mathrm{m}$ from the $\operatorname{AuIn}_{2} / \mathrm{AuIn}$ interface after 144 and $225 \mathrm{~h}$, respectively.

\subsubsection{Experiments at $250^{\circ} \mathrm{C}$}

At $250{ }^{\circ} \mathrm{C}$ the same three IMCs are observed, even after short reaction times (Fig. 4). The saturation of the In bath over a long time period is difficult due to the large difference between the $\mathrm{Au}$ and In densities $\left(\rho_{\mathrm{Au}}=19.3\right.$ and $\rho_{\text {In }}=7.3 \mathrm{~g} / \mathrm{cm}^{3}$ ). Thus, convection movements cannot be avoided and $\mathrm{AuIn}_{2}$ grains, which are not very compact and heavier than In, have a tendency to detach from the wire and deposit at the bottom of the crucible. An additional experiment with a reaction time of $7 \mathrm{~h}$ was also performed with an alternative setup, the saturated liquid In in this case being poured onto a gold plate. The $\psi$ phase, which is not stable below $224.3^{\circ} \mathrm{C}$ (Fig. 1), is present in this sample as a thin layer between $\mathrm{Au}_{7} \mathrm{In}_{3}$ and $\mathrm{AuIn}$ 


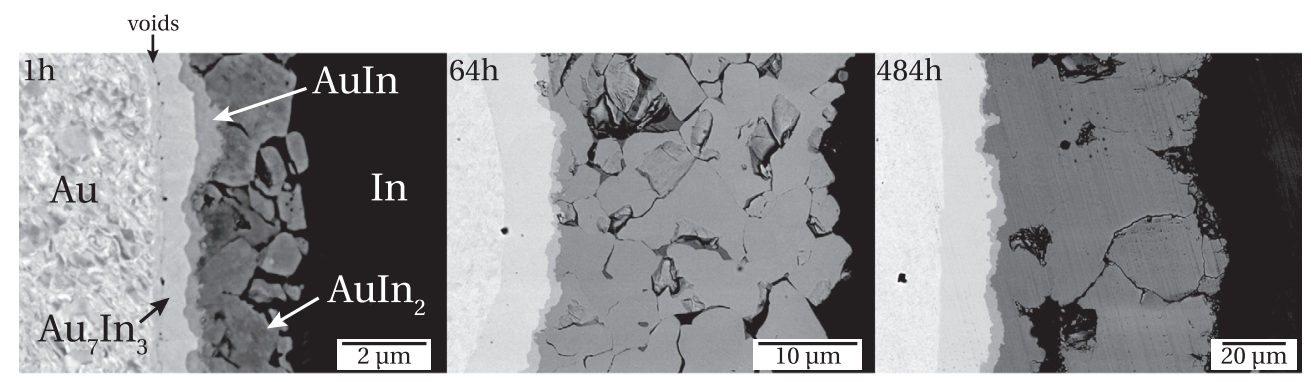

Fig. 2. SEM/BSE micrographs of IMCs after reaction at $150^{\circ} \mathrm{C}$ for 1 (left), 64 (center) and $484 \mathrm{~h}$ (right). Gold (left) and indium (right) are separated from left to right by distinct layers of $\mathrm{Au}_{7} \mathrm{In}_{3}, \mathrm{AuIn}$ and $\mathrm{AuIn}_{2}$.

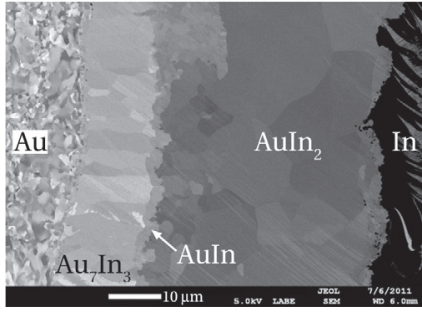

(a) general view

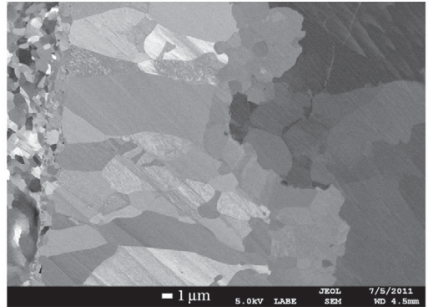

(b) $\mathrm{Au}_{7} \mathrm{In}_{3}$ and $\mathrm{AuIn}$

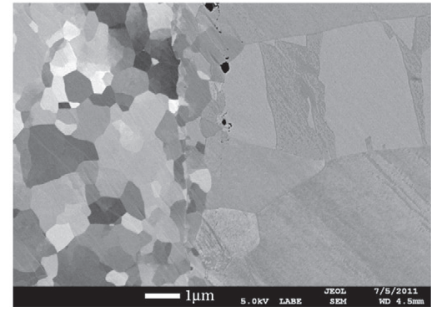

(c) $\mathrm{Au} / \mathrm{Au}_{7} \mathrm{In}_{3}$ interface

Fig. 3. SEM/LABE micrographs of the sample treated for $324 \mathrm{~h}$ at $150{ }^{\circ} \mathrm{C}$ showing crystallographic contrast; $\mathrm{Au}_{7} \mathrm{In}_{3}$ growth is columnar whereas the growth of AuIn and $\mathrm{AuIn}_{2}$ is equiaxed.
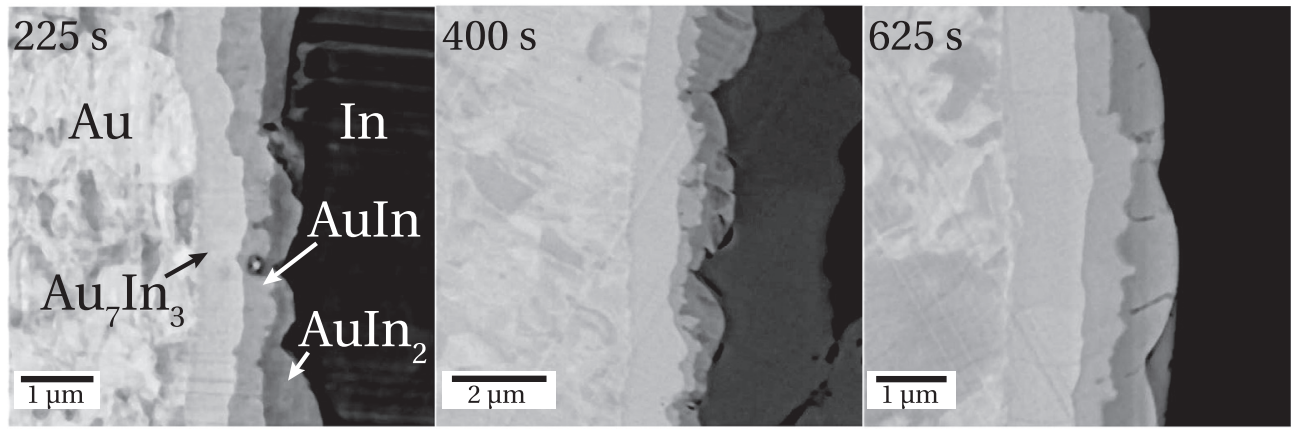

Fig. 4. SEM/BSE micrographs of IMCs growing at $250^{\circ} \mathrm{C}$. Gold (left) and indium (right) are separated from left to right by distinct layers of $\mathrm{Au}_{7} \mathrm{In}_{3}$, AuIn and AuIn
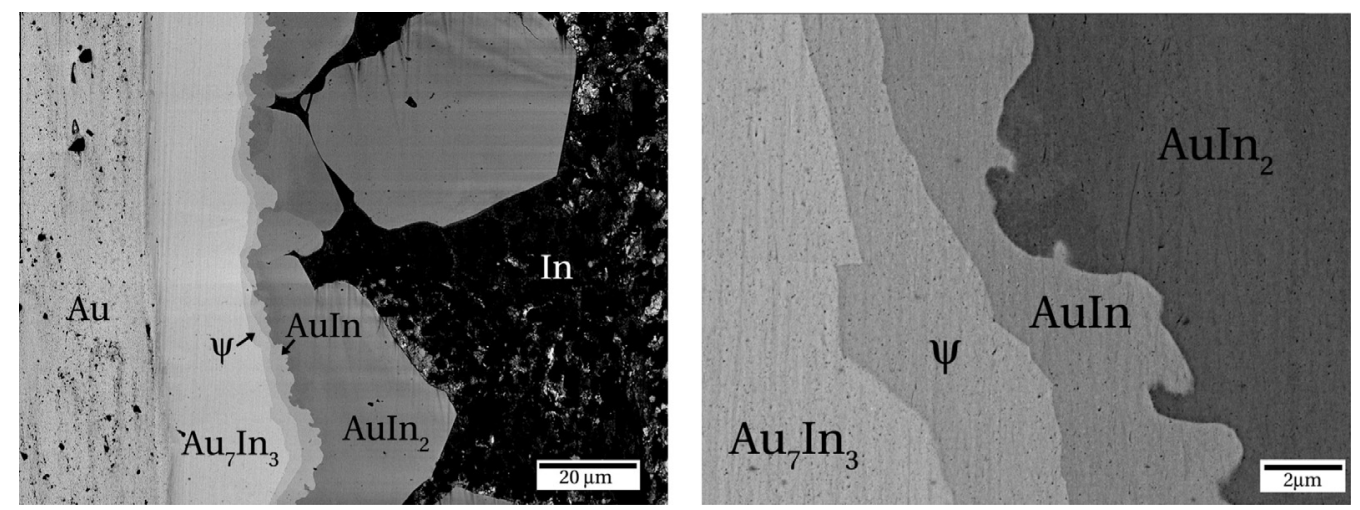

Fig. 5. SEM/BSE micrographs after $7 \mathrm{~h}$ at $250{ }^{\circ} \mathrm{C}$ with a horizontal configuration where the saturated liquid indium is poured onto gold: general view (left) and detailed view (right). From left to right: $\mathrm{Au}_{7} \mathrm{In}_{3, \psi}$, AuIn and $\mathrm{AuIn}_{2}$. 
(Fig. 5). To our knowledge, this is the first time that the $\psi$ phase has been observed in an $\mathrm{Au}-\mathrm{In}$ diffusion couple.

\subsection{Growth kinetics}

The average thicknesses of the three IMCs were measured on several SEM micrographs along the interface for each diffusion time and temperature. The measurements were done based on the different grey levels coming from the BSE contrast. Given the observed growth irregularities, especially for the $\mathrm{AuIn}_{2}$ layer, care was taken to perform sufficient measurements in order to obtain representative values.

For both temperatures, the IMCs thicknesses $(\Delta x)$ are plotted as a function of the square root of the reaction time in Fig. 6, where the error bars correspond to the standard deviations of the measurements. As can be seen, the expected parabolic law is well respected for all the IMCs at $150{ }^{\circ} \mathrm{C}$ (left figure): least-squares fits of these data with a power-law function $a t^{n}$ give $n=0.53,0.44$ and 0.53 for $\mathrm{Au}_{7} \mathrm{In}_{3}, \mathrm{AuIn}$, and $\mathrm{AuIn} \mathrm{In}_{2}$ respectively. These fits almost correspond to the parabolic fits drawn as dashed lines in Fig. 6 (left). We can further observe that the irregular aspect of $\mathrm{AuIn}_{2}$ induces more scattering in the data.

At $250{ }^{\circ} \mathrm{C}$, the measured thicknesses of $\mathrm{AuIn}_{2}$ are very likely underestimated at short reaction times due to the detachment and sedimentation of the grains (see the enlarged view shown in the inset of Fig. 6, right). The least-squares fit exponents $n$ at this temperature are 0.48 for $\mathrm{AuIn}$ and 0.78 for $\mathrm{Au}_{7} \mathrm{In}_{3}$. The latter value does not agree with a parabolic growth law and thus does not correspond to the straight line shown in Fig. 6 (right). Note that the measured thicknesses of $\mathrm{Au}_{7} \mathrm{In}_{3}$ are too small at short times, but the differences with a parabolic fit (straight lines) are only $1-2 \mu \mathrm{m}$.

The growth constants $\left(K=\Delta x^{2} / t\right)$ in Fig. 6 for each IMC are listed in Table 2. The growth constant of $\mathrm{AuIn}_{2}$
Table 2

Growth constants $K\left[\mathrm{~m}^{2} \mathrm{~s}^{-1}\right]$ of IMCs formed at $150{ }^{\circ} \mathrm{C}$ and $250{ }^{\circ} \mathrm{C}$.

\begin{tabular}{lll}
\hline & $150^{\circ} \mathrm{C}$ & $250^{\circ} \mathrm{C}$ \\
\hline $\mathrm{Au}_{7} \mathrm{In}_{3}$ & $1.7 \pm 0.1 \times 10^{-16}$ & $1.3 \pm 0.2 \times 10^{-14}$ \\
$\mathrm{AuIn}$ & $9.8 \pm 1.6 \times 10^{-18}$ & $2.45 \pm 0.1 \times 10^{-16}$ \\
$\mathrm{AuIn}$ & $2.3 \pm 0.2 \times 10^{-15}$ & $5.5 \times 10^{-14}$ \\
\hline
\end{tabular}

at $250{ }^{\circ} \mathrm{C}$ is close to the value found by Liu and Chuang [7] with initially pure $\operatorname{In}\left(3 \times 10^{-14} \mathrm{~m}^{2} \mathrm{~s}^{-1}\right)$, despite the fact that it was calculated only from the thickness measured after $7 \mathrm{~h}$.

\subsection{Diffusion profiles in $A u$}

Fig. 7 shows the results of SIMS depth profiles measured in gold for two samples heat-treated for $484 \mathrm{~h}$ at $150{ }^{\circ} \mathrm{C}$ (left) and for $7 \mathrm{~h}$ at $250^{\circ} \mathrm{C}$ (right). The experimental data were fitted with the exact analytical solution of the diffusion equation assuming a constant concentration $C_{A u}^{*}$ at a motionless interface, with the boundary conditions $C(x, t=0)=0$ and $C(\infty, t)=0$ :

$C(x, t)=C_{A u}^{*} \operatorname{erfc}\left(\frac{x}{2 \sqrt{D^{4 u} t}}\right)$

where erfc is the complementary error function, $D^{A u}$ is the diffusion coefficient of $\mathrm{In}$ in $\mathrm{Au}$ and $C_{A u}^{*}$ is the concentration of $\mathrm{In}$ in $\mathrm{Au}$ at the interface with $\mathrm{Au}_{7} \mathrm{In}_{3}$. Since these SIMS measurements were made on inclined sections in order to limit the sputtering time, the bevel angles had to be accounted for in the deconvolution of the results. In contrast, the cylindrical geometry of the first sample was ignored, the size of the analyzed area $\left(\sim 50 \times 50 \mu \mathrm{m}^{2}\right)$ being small compared to the wire radius $(0.5 \mathrm{~mm})$. The fits give a value of $D^{4 u}$ at $150^{\circ} \mathrm{C}$ of $10^{-18} \mathrm{~m}^{2} \mathrm{~s}^{-1}$, i.e. a value about 0.15 times that found by Powell and Braun [4], while at $250{ }^{\circ} \mathrm{C} D^{4 u}=2 \times 10^{-17} \mathrm{~m}^{2} \mathrm{~s}^{-1}$.
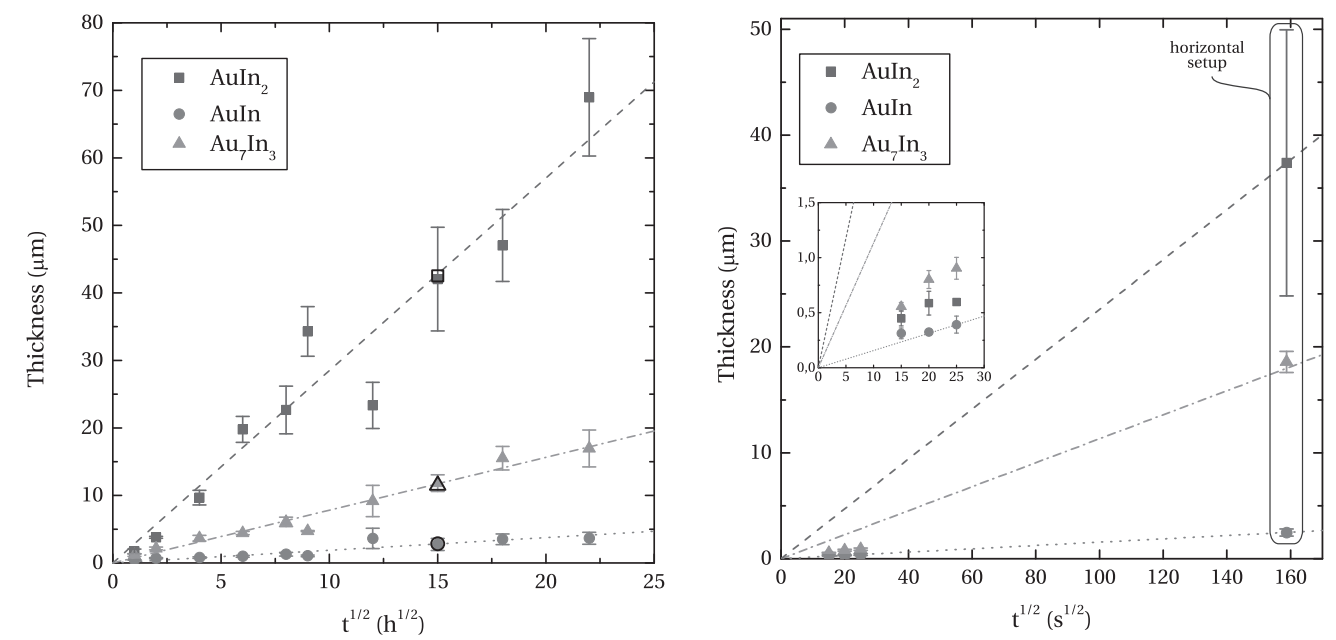

Fig. 6. IMCs growth: measured thickness vs square root of the diffusion time at $150{ }^{\circ} \mathrm{C}$ (left) and $250{ }^{\circ} \mathrm{C}$ (right). Filled squares, circles and triangles correspond to the measured thicknesses of $\mathrm{AuIn}_{2}$, AuIn and $\mathrm{Au}_{7} \mathrm{In}_{3}$, respectively, while the open symbols after $225 \mathrm{~h}$ of reaction in the left figure correspond to the simulation shown in Fig. 8 (right). 

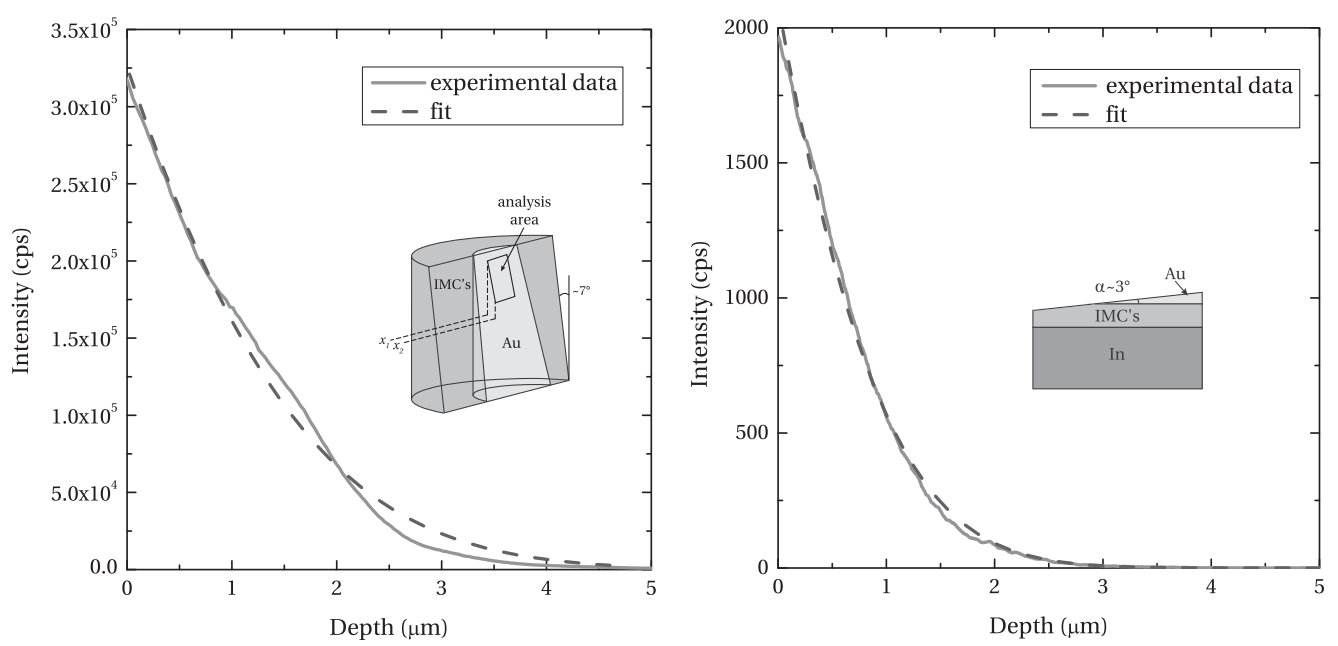

Fig. 7. Indium profiles in Au: experimental data and fits with Eq. (1), taking into account the inclined section. Left: $484 \mathrm{~h}$ at $150{ }^{\circ} \mathrm{C}$ (DSIMS); right: $7 \mathrm{~h}$ at $250^{\circ} \mathrm{C}$ (ToF-SIMS).

\section{Modeling of IMCs growth}

\subsection{FDM model}

The diffusion couples being supposed to be isothermal, the growth of the various IMCs is governed by solute diffusion, and possibly interface kinetics if their velocities are high. A numerical model was developed to solve the diffusion equations in the various phases, i.e. $\mathrm{Au}$ and the three IMCs, in order to reproduce the growth of the IMCs. The main assumptions of the model are: (i) diffusion of In is supposed to occur much faster than the diffusion of $\mathrm{Au}$; (ii) no consideration of the nucleation stage of the IMCs; (iii) local equilibrium at the interfaces (i.e. no interface kinetics contribution); (iv) liquid indium initially saturated with gold; and (v) linear variation of the chemical potential across each IMC, given by the difference of the equilibrium chemical potentials with the neighboring phases on each side of the IMC, divided by its thickness.

The diffusion of In into the $\mathrm{Au}$ phase was computed using a front-tracking 1-D numerical model to solve Fick's second law in the moving reference frame $x \in\left[0, x^{*}(t)\right]$, after a Landau transformation into a fixed reference frame $\eta(x, t)=x / x^{*}(t) \in[0,1]$, where $x^{*}$ is the position of the $\mathrm{Au} /$ $\mathrm{Au}_{7} \mathrm{In}_{3}$ interface (see Ref. [9]). The diffusion equation of In in the $\mathrm{Au}$ phase then becomes:

$\left(\frac{\partial C}{\partial t}\right)_{x}=\left(\frac{\partial C}{\partial t}\right)_{\eta}-\frac{v^{*} \eta}{x^{*}}\left(\frac{\partial C}{\partial \eta}\right)_{t}=\frac{1}{x^{* 2}} \frac{\partial}{\partial \eta}\left(D^{A u} \frac{\partial C}{\partial \eta}\right)_{t}$

where $C(x, t)$ is the In concentration (in at $\mathrm{m}^{-3}$ ), $D^{A u}$ is the diffusion coefficient of In in Au and $v^{*}$ is the velocity of the $\mathrm{Au} / \mathrm{Au}_{7} \mathrm{In}_{3}$ interface. Note the appearance of an advection term associated with the movement of the $\mathrm{Au} / \mathrm{Au}_{7} \mathrm{In}_{3}$ interface. This equation was solved numerically with a fixed interval and number of mesh points using an explicit scheme and a Neumann boundary condition in $x=0$.
For the mesh point " $\mathrm{i}$ ", the equation to be solved in the gold phase becomes:

$$
\begin{aligned}
\frac{C_{i}^{t+\Delta t}-C_{i}^{t}}{\Delta t}= & D^{A u} \frac{C_{i+1}-2 C_{i}+C_{i-1}}{\left(x^{*} \times \Delta \eta\right)^{2}}+\frac{v^{*} \times(i-1) \times \Delta \eta}{x^{*}} \\
& \times \frac{\left(C_{i+1}-C_{i-1}\right)}{2 \Delta \eta}
\end{aligned}
$$

The flux of indium in gold at the $\mathrm{Au} / \mathrm{Au}_{7} \mathrm{In}_{3}$ interface was then calculated as:

$J^{A u}=-D^{A u} \frac{C_{2}-C_{1}}{\Delta \eta \times x^{*}}$

The In fluxes in the IMCs were calculated from chemical potential gradients since these phases are stoichiometric. The IMCs possess very sharp free energy curves; consequently, a very slight change in composition results in a large variation of the chemical potential. The atomic flux in the IMC $\alpha$ in that case is given by:

$J^{\alpha}=-M^{\alpha} C^{\alpha} \frac{\Delta \mu^{\alpha}}{\Delta x^{\alpha}}$

where $M^{\alpha}$ is the atomic mobility of In in the IMC $\alpha, C^{\alpha}$ is its (stoechiometric) composition and $\Delta \mu^{\alpha}$ is the chemical potential difference across its thickness $\Delta x^{\alpha}$. In order to make the discussion and comparisons easier, the atomic mobilities $M^{\alpha}$ were converted into equivalent diffusion coefficients, $D^{\alpha}$, assuming that the IMCs can be treated as regular solutions, using the following relationship:

$D^{\alpha}=M^{\alpha} R T\left(1-\frac{2 \Delta H_{m i x}^{\alpha}}{R T}\right)$

where $R$ is the gas constant, $T$ is the temperature and $\Delta H_{m i x}^{\alpha}$ is the enthalpy of mixing (values taken from Ref. [8]). The velocity of an $\alpha-\beta$ interface, $v_{\alpha \beta}$, is finally obtained by the application of mass and solute conservation equations (see Ref. [10]): 
$\left(\rho^{\beta}-\rho^{\alpha}\right) v_{\alpha \beta}=\rho^{\beta} v_{\beta}-\rho^{\alpha} v_{\alpha}$

$\rho^{\beta} C_{\beta}^{*}\left(v_{\beta}-v_{\alpha \beta}\right)-\rho^{\alpha} C_{\alpha}^{*}\left(v_{\alpha}-v_{\alpha \beta}\right)=j^{\alpha *}-j^{\beta *}$

where $\rho^{v}$ and $v_{v}$ are the density and velocity in the phase $v$, respectively, while $C_{v}^{*}$ and $j^{v *}$ are the interfacial concentration and mass flux at the interface position in the phase $v$. The density differences are taken into account, thus allowing one to predict the evolution of the overall size of the system, which is an important parameter for a finite domain such as that encountered in SLID bonding. The equations were solved assuming the velocity in gold, $v_{A u}$, to be zero.

The starting configuration was made of $60 \mu \mathrm{m}$ of gold and $80 \mu \mathrm{m}$ of saturated indium separated by thin layers $(0.05 \mu \mathrm{m})$ of $\mathrm{Au}_{7} \mathrm{In}_{3}, \mathrm{AuIn}$ and $\mathrm{AuIn}$. The initial mesh size in the Au phase was set to $60 \mathrm{~nm}$, with 1000 mesh points. The results were shown to be independent of the mesh size as the growth constants were found to be identical with an initial mesh size of $4 \mathrm{~nm}$. Thermodynamic data were computed based on the work of Liu et al. [8].

\subsection{Optimization of the diffusion coefficients}

The diffusion coefficients were adjusted to reproduce the growth constants obtained experimentally. In addition to the evolution of the IMC thicknesses, their position with respect to the initial gold-indium interface position was used as an additional parameter to be fitted by the simulation. This then gives the same number of parameters to be fitted (i.e. the four diffusion coefficients in the three IMCs and gold, indium being saturated) as the number of observable entities (three IMC thicknesses and a reference position).

As an example, Fig. 8 (left) shows an SEM/BSE micrograph of a sample maintained for $225 \mathrm{~h}$ at $150^{\circ} \mathrm{C}$, for which the gold wire surface was partially protected by the application of an epoxy enamel (Berlapoxy ${ }^{\mathrm{TM}}$ ) before its immersion in the indium bath. The original $\mathrm{Au} / \mathrm{In}$ interface is extended in the reaction zone by the dashed white circle. As already stated in the previous section, the initial $\mathrm{Au} / \mathrm{In}$ interface is located in the $\mathrm{AuIn}_{2}$ compound, at a mean distance of about $10 \mu \mathrm{m}$ from the $\mathrm{AuIn}_{2} / \mathrm{AuIn}$ interface after $225 \mathrm{~h}$. The corresponding simulated growth of IMCs at $150{ }^{\circ} \mathrm{C}$ is shown on the right of Fig. 8 as a function of time. The original interface is shown with a dashed black line, and its position with respect to the $\mathrm{AuIn}_{2} / \mathrm{AuIn}$ interface corresponds fairly well to the observation on the left. The predicted thicknesses of the various IMCs after $225 \mathrm{~h}$ at $150{ }^{\circ} \mathrm{C}$ are $42.5,2.8$ and $11.5 \mu \mathrm{m}$ for $\mathrm{AuIn}_{2}$, AuIn and $\mathrm{Au}_{7} \mathrm{In}_{3}$, respectively. These values, shown with open symbols in Fig. 6 (left), agree very well with the parabolic law fitted to the experimental data.

Diffusion being a thermally activated process, the diffusion coefficients can be expressed as a function of temperature using an Arrhenius equation:

$D(T)=D_{0} \exp \left(-\frac{E_{a}}{R T}\right)$

The pre-exponential factors $D_{0}$ and activation energies $E_{a}$ for the diffusion of In in the different phases are listed in Table 3. It is notable that the activation energy for the diffusion across $\mathrm{Au}_{7} \mathrm{In}_{3}$ is larger than that for diffusion across the other phases. Errors on $D$ are estimated from the errors on the experimental growth constants and thus no error is given for the diffusion coefficient in the gold phase. The estimated errors on the pre-exponential factors are large, as they are computed from extremal values of $\ln \left(D_{0}\right)$.

\section{Discussion}

\subsection{Porosity formation}

Microporosity was observed near the $\mathrm{Au} / \mathrm{Au}_{7} \mathrm{In}_{3}$ interface, in the $\mathrm{Au}_{7} \mathrm{In}_{3}$ phase. It has a very small size (typically on the order of $0.15 \mu \mathrm{m}$ ) and is intragranular. A few such pores are visible in the middle of Fig. 3(c) and in Fig. 9(a). By serial sectioning using a focused ion beam (FIB), it was observed that this microporosity is located in a plane more or less parallel to the $\mathrm{Au} / \mathrm{Au}_{7} \mathrm{In}_{3}$ interface (Fig. 9(b)). At $150{ }^{\circ} \mathrm{C}$, the distance $\delta_{p}$ of this porosity "plane" to the $\mathrm{Au} / \mathrm{Au}_{7} \mathrm{In}_{3}$ interface also increases with
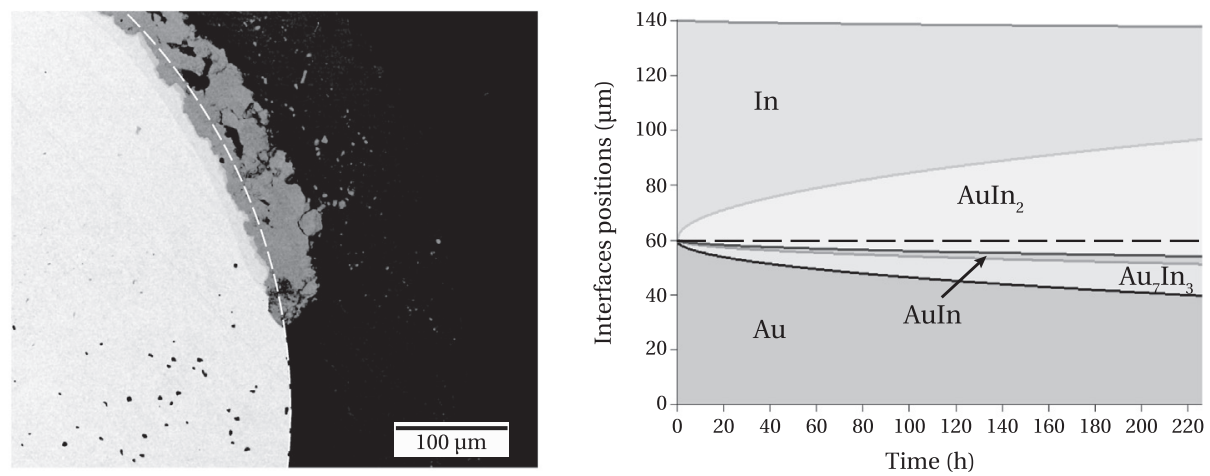

Fig. 8. Left: SEM/BSE micrograph after $225 \mathrm{~h}$ at $150^{\circ} \mathrm{C}$; the initial $\mathrm{Au} / \mathrm{In}$ interface was marked prior to experiment and its position is represented by the dashed white line. Right: IMC growth simulated at the same temperature; the dashed black line indicates the original Au/In interface. 
Table 3

Pre-exponential factors $D_{0}$ and activation energies $E_{a}$ for In diffusion.

\begin{tabular}{lllllll}
\hline & $D_{0}\left[\mathrm{~m}^{2} \mathrm{~s}^{-1}\right]$ & & & \multicolumn{3}{c}{$E_{a}[\mathrm{~kJ} / \mathrm{mol}]$} \\
\hline $\mathrm{AuIn}_{2}$ & $5.2 \times 10^{-8}$ & + & $6.1 \times 10^{-8}$ & 61.3 & + & 3.0 \\
& & - & $3.1 \times 10^{-8}$ & & - & 3.4 \\
\multirow{2}{*}{$\mathrm{AuIn}$} & $3.1 \times 10^{-9}$ & + & $1.5 \times 10^{-9}$ & 57.5 & + & 1.1 \\
& & - & $1.0 \times 10^{-9}$ & & - & 1.0 \\
$\mathrm{Au}_{7} \mathrm{In}_{3}$ & $4.05 \times 10^{-7}$ & + & $8.15 \times 10^{-7}$ & 72.0 & + & 3.7 \\
& & - & $2.85 \times 10^{-7}$ & & - & 4.1 \\
$\mathrm{Au}$ & $6.9 \times 10^{-10}$ & & & 64.5 & & \\
\hline
\end{tabular}

the square root of the diffusion time, following the law: $\delta_{p}(t)[\mu m]=1.67 \times 10^{-3} t^{1 / 2}[s]$. The size and location of this microporosity indicate that it probably results from a Kirkendall effect, and not from a density difference $\left(\rho_{A u_{7} I n_{3}}<\rho_{A u}\right)$. However, it is difficult to assess the importance of this effect in the present case for at least two reasons: (i) a flux of vacancies due to a difference between the diffusion coefficients of $\mathrm{Au}$ and In can indeed lead to the formation of microporosity if the vacancies condense into micropores, but the vacancies can also modify the absolute position of the interfaces if they can be annihilated (e.g. by dislocation climb). Therefore, the absolute position of an interface, which depends on the change in density (accounted for in the present investigation), is also linked to the Kirkendall effect (ignored here); and (ii) there are three IMCs involved in addition to the $\mathrm{Au}$ and In phases, and thus four interfaces with only one known absolute reference position, namely the initial position of the $\mathrm{Au} / \mathrm{In}$ interface. This reference position has already been used in the estimation of the diffusion coefficients and mobilities, and thus cannot provide additional information on the Kirkendall effect.

\subsection{Diffusion and growth}

Except for the indium phase, the two temperatures at which the diffusion couple experiments were made are lower than $3 / 4$ of the melting point of the observed phases (in $\mathrm{K}$ ). Therefore, diffusion is expected to occur mainly along grain boundaries [11]. According to the studies mentioned above, $\mathrm{AuIn}_{2}$ grows mainly by diffusion of In atoms and reaction at the interface with AuIn. If the diffusion of $\mathrm{Au}$ atoms is much slower, this results in a net flux of vacancies in the opposite direction (Kirkendall effect).

Diffusion along $\mathrm{Au}_{7} \mathrm{In}_{3}$ grain boundaries is made easier thanks to its columnar structure. The presence and location of porosity suggest that the diffusion of $\mathrm{Au}$ atoms through $\mathrm{Au}_{7} \mathrm{In}_{3}$ is faster than the diffusion of In. A schematic of the diffusion across the various phases is shown in Fig. 10. It appears that AuIn acts as a barrier for both In diffusing to the left and $\mathrm{Au}$ diffusing to the right. This phenomenon is reflected in both the very low growth rate of this IMC (Table 2) and and the low In diffusion coefficient (Table 3).

The modelling assumption that In can be considered as the only diffusing species does not seem to hold for $\mathrm{Au}_{7} \mathrm{In}_{3}$. Consequently, the estimated diffusion coefficients of In through this IMC are most likely overestimated, the values including also diffusion of $\mathrm{Au}$ atoms.

The diffusion coefficients of In in gold predicted by the model on the basis of the IMC growth kinetics can be compared with the SIMS experimental results. At $150^{\circ} \mathrm{C}$, the SIMS analyses provide a value of $D^{4 u}$ equal to $10^{-18} \mathrm{~m}^{2} \mathrm{~s}^{-1}$. By means of the numerical model, we determine a value three times lower: $D^{4 u}=3 \times 10^{-19} \mathrm{~m}^{2} \mathrm{~s}^{-1}$. However, there is a lack of accuracy concerning this experimental result

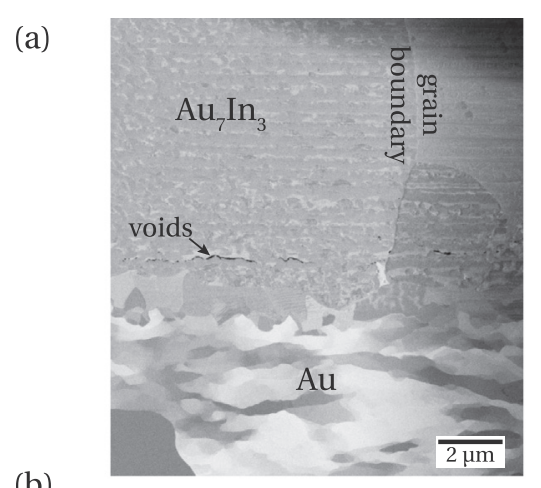

(b)

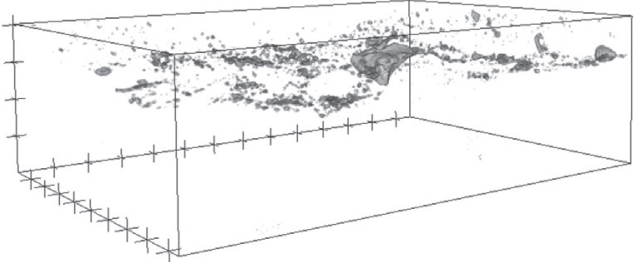

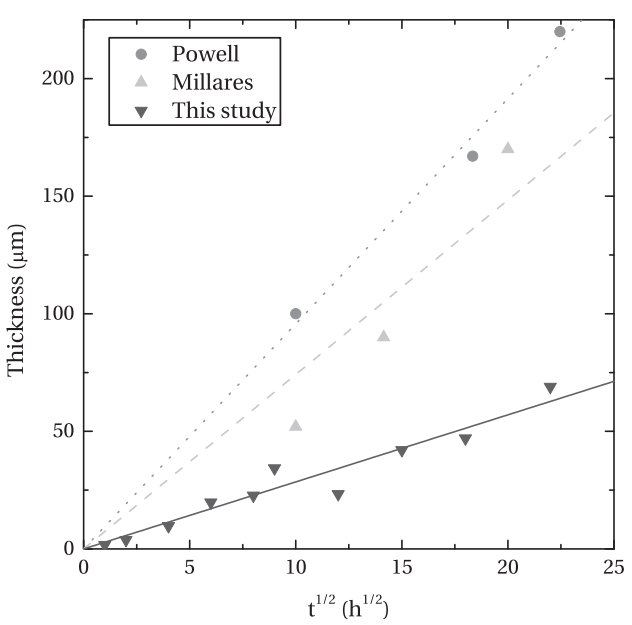

Fig. 9. Left: (a) location of the porosity observed in $\mathrm{Au}_{7} \mathrm{In}_{3}$ at $250{ }^{\circ} \mathrm{C}$ after $7 \mathrm{~h}$ (SEM/energy selective backscattered) and (b) 3-D reconstruction of this porosity using a FIB. The graduation in (b) corresponds to $1 \mu \mathrm{m}$ and the $\mathrm{Au} / \mathrm{Au}_{7} \mathrm{In}_{3}$ interface is below the porosity in both figures. Right: comparison of the results obtained for $\mathrm{AuIn}_{2}$ and those reported in the literature $[4,6]$. 


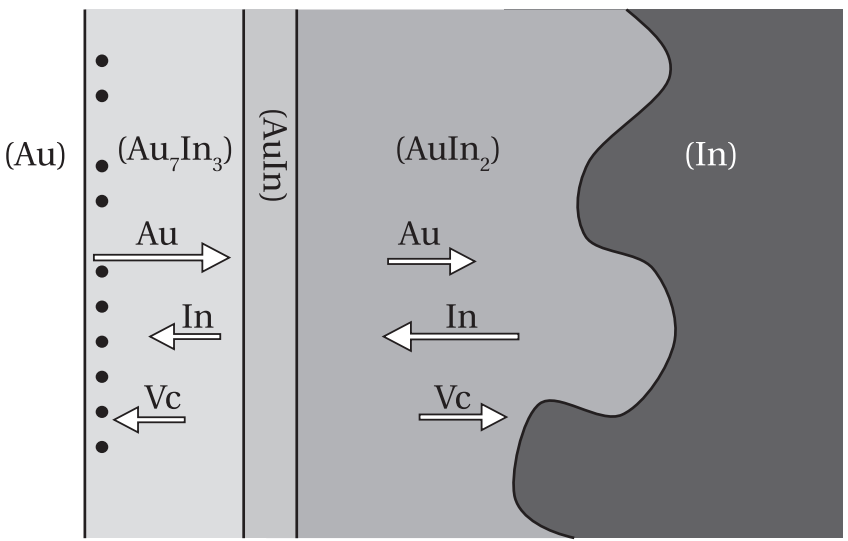

Fig. 10. Schematic of $\mathrm{Au}, \mathrm{In}$ and vacancy diffusion in the Au-In system.

and, consequently, we did not use it to fit the value implemented in the model. At $250{ }^{\circ} \mathrm{C}$, fitting the SIMS data gives $D^{4 u}=2 \times 10^{-17} \mathrm{~m}^{2} \mathrm{~s}^{-1}$, while an adjustment of the parameters of the model predicts a value about half of that $\left(D^{4 u}=8 \times 10^{-18} \mathrm{~m}^{2} \mathrm{~s}^{-1}\right)$.

The diffusion coefficients at $150{ }^{\circ} \mathrm{C}$ can also be compared to the results from Powell and Braun [4]. These authors determined values of $\widetilde{D}$ from a Matano analysis assuming a homogeneity range of 10 at. $\%$ for each IMC. The method then used to extract the diffusion coefficients of In is, however, not explained. In the IMCs, these values of $D$ are slightly larger than the values obtained in the present study. The difference is more important in gold, where an order of magnitude separates the values. We noted that our results are actually closer to the values of $\widetilde{D}$ from Powell and Braun.

The influence of the Au microstructure on In diffusion, and thus on IMCs growth, is not part of this study since the Au substrates used are not significantly different in terms of grain size. However, the diffusion of In in Au is very limited and the microstructure of $\mathrm{Au}_{7} \mathrm{In}_{3}$ is not related to the $\mathrm{Au}$ microstructure. Consequently, the IMC growth seems to be mainly controlled by the diffusion through them. The simulations confirm this result as they give growth constants that are not very sensitive to the choice of $D_{A u}$.

\subsection{Comparison of $\mathrm{AuIn}_{2}$ growth with literature data}

There is no study available in the literature concerning the growth of $\mathrm{AuIn}$ and $\mathrm{Au}_{7} \mathrm{In}_{3}$, but the growth kinetics of $\mathrm{AuIn}_{2}$ determined in the present work can be compared with former studies (Fig. 9, right). At $150^{\circ} \mathrm{C}$, the kinetics obtained in the present study is slower than the kinetics previously reported. This discrepancy might come from a larger $\mathrm{AuIn}_{2}$ grain structure which can slow down the diffusion process. With an average size approaching $15 \mu \mathrm{m}$ after $324 \mathrm{~h}$, the observed $\mathrm{AuIn}_{2}$ grains are substantially larger than in other studies. Millares et al. [6], for example, reported a grain size of 2-4 $\mu \mathrm{m}$ independent of diffusion time, whereas they measured a grain size similar to our results for the other IMCs. In the present study, it seems that the $\mathrm{AuIn}_{2}$ grains are smaller in the experiments conducted with the $100 \mu \mathrm{m}$ diameter gold wires, and this IMC is also less compact in this case. While coarsening of the grains may occur, it is probably not the reason for this discrepancy and we do not have any explanation for the differences in $\mathrm{AuIn}_{2}$ microstructures.

\section{Conclusion}

A number of conclusions can be drawn from the $\mathrm{Au}-\mathrm{In}$ diffusion couples experiments:

- $A u I n_{2}, A u I n$ and $A_{7} I_{3}$ are the three IMCs that are always observed at 150 and $250{ }^{\circ} \mathrm{C}$ regardless of the diffusion time. Their growth was shown to follow the expected parabolic law at both temperatures. AuIn 2 forms the majority of the reaction zone and grows irregularly, forming blocky grains. $\mathrm{Au}_{7} \mathrm{In}_{3}$ is the second IMC in terms of thickness and grows much more regularly, with a nearly flat interface with Au. AuIn was only observed as a thin layer and seems to act to some extent as a diffusion barrier for both In and Au.

- At $250{ }^{\circ} \mathrm{C}$, an additional thin layer of $\psi$ is also present after $7 \mathrm{~h}$ when a horizontal configuration of the diffusion couple is adopted.

- SEM observations with a LABE detector allowed us to visualize the microstructure of the IMCs: $\mathrm{Au}_{7} \mathrm{In}_{3}$ grows in a columnar way, whereas both $\mathrm{AuIn}_{2}$ and AuIn have an equiaxed grain morphology.

- Au atoms appear to diffuse much faster than In through $\mathrm{Au}_{7} \mathrm{In}_{3}$. This conclusion is based on the observed porosity, which probably results from a Kirkendall effect.

- The diffusion of In in Au is very slow and the growth of the IMCs seems to be mainly controlled by the diffusion through them.

The main results and limitations of the 1-D numerical model developed can be summarized as follows:

- The model reproduces the observed experimental growth well and provides values of the indium diffusion coefficients that are of reasonable orders of magnitude.

- The model tends to confirm that the growth of the IMCs is mainly controlled by the diffusion through them as their growth is not significantly affected by the value used for the diffusion coefficient of In in Au.

- As the model is monodimensional, the growth instabilities are not taken into account. This does not represent a major limitation for $\mathrm{Au}_{7} \mathrm{In}_{3}$ and AuIn since their growth is rather regular. By contrast, $\mathrm{AuIn}_{2}$ was shown to grow irregularly and the description of this IMC is thus more limited: only the evolution of its average thickness can be reproduced.

- The assumption was made that we could ignore the diffusion of $\mathrm{Au}$ and only consider the diffusion of In, which is apparently not true for $\mathrm{Au}_{7} \mathrm{In}_{3}$. The obtained diffusion coefficients are effective diffusion coefficients which take into account the different contributions to diffusion. 


\section{Acknowledgments}

The Swatch Group R\&D S.A., division Asulab, is gratefully acknowledged for funding this work. The authors also thank JEOL for the CSP polishing and LABE imaging, and CAMECA for the DSIMS analyses.

\section{References}

[1] Bernstein L. J Electrochem Soc 1966;113:1282.

[2] Bernstein L, Bartholomew H. Trans Metall Soc AIME 1966;236: 405 .
[3] Okamoto H, Massalski T. Binary alloy phase diagrams. 2nd ed. Metals Park, OH: ASM; 1990.

[4] Powell GW, Braun JD. Trans Metall Soc AIME 1964;230:694.

[5] Jellison JE. Technical Report NASA GSFC Code 313. Materials Control and Applications Branch; 1979.

[6] Millares M, Pieraggi B, Lelievre E. Solid State Ion 1993;63-65:575.

[7] Liu Y, Chuang T. J Electron Mater 2000;29:405.

[8] Liu HS, Cui Y, Ishida K, Jin ZP. CALPHAD 2003;27:27.

[9] Rappaz M, Bellet M, Deville M. Traité des matériaux. Modélisation numérique en science et génie des matériaux, vol. 10. Lausanne: Presses Polytechniques et Universitaires Romandes; 1998.

[10] Dantzig JA, Rappaz M. Solidification. Lausanne: EPFL Press; 2009.

[11] Philibert J. Diffusion et transport de matière dans les solides. Les Ulis: Ed. de Physique; 1990. 